\title{
TRAINING IN RENDERING AND TRANSLATION AT NON-LINGUISTIC FACULTIES DURING THE 2020 PANDEMIC
}

\author{
Irina Meshkova ${ }^{1}$, Olga Sheremetieva ${ }^{2}$, Larissa Spynu ${ }^{3}$ \\ ${ }^{1}$ Assoc Prof., PhD RUDN University, RUSSIA, meshiran1@gmail.com \\ ${ }^{2}$ Senior Lecturer RUDN University, RUSSIA, oasher@mail.ru \\ ${ }^{3}$ Assoc Prof., PhD RUDN University, RUSSIA, lorance@rambler.ru
}

\begin{abstract}
The article is devoted to the peculiarities of teaching French at non-linguistic faculties, the analysis of the concepts of rendering, retelling (resumé, compte-rendu, synthèse), rendering translation of texts using an interdisciplinary approach in the context of the development of digital technologies in the modern educational space, in particular, during the Covid-19 pandemic. Extraordinary circumstances have set before teachers from many countries of the world, including Russian teachers, the task of modernizing pedagogical processes as part of the transition to a distance learning format using one or another electronic educational platform. The problem arises from integrating educational and methodological materials into the concept of distance learning, taking into account various digital resources and stages of development of information and communication technologies. A distinctive feature of the situation is the blurring of boundaries between traditional and distance approaches both in whole education, and in particular in teaching foreign languages.

Teaching rendering as the most important type of speech activity, working with foreign language texts for the purpose of their subsequent rendering, is necessary to prepare students for research activities. Rendering translation plays an important teaching role and has significant potential. In the French language classes at the non-linguistic faculties of the RUDN University, texts of various genres are offered for rendering translation, for example, literary, journalistic, as well as scientific texts on relevant topics. As a result, students must learn to submit an informative abstract/summary (summary-synopsis), which contains in a generalized form all the main provisions of the original text. In the course of rendering translation, the student carries out semantic or informational processing of the text, learns to avoid violations of the theme-rhematic sequence, maintain the coherence of the text, correctly organizing information in paragraphs and preserving subject-logical connections. In addition to the skills of rendering translation, students are trained in language mediation, which is carried out by reformulating it in the form of a resume or report.

The use of digital educational technologies and traditional pedagogical approaches within the framework of ensuring the concept of lifelong education helps to solve the problem, regardless of the location of the teacher and student. Under the conditions of distance learning during the COVID 19 period, the authors developed and successfully applied a system of exercises and tasks aimed at the formation and development of rendering skills, rendering translation, language mediation in French classes for students of non-linguistic faculties of RUDN University.
\end{abstract}

Keywords: rendering skills, non-linguistic faculties, foreign languages, the Covid-19 pandemic, a distance learning format. 


\section{INTRODUCTION}

The article is devoted to the peculiarities of teaching translation and summarization of special Frenchlanguage texts at non-linguistic faculties, the concept of text summarization within the framework of interlanguage transformation using an interdisciplinary approach in the context of the development of digital technologies in education, in particular, during the Covid-19 pandemic, is analyzed. Extraordinary circumstances set before teachers the task of modernizing pedagogical processes, partial transition to a distance learning format using one or another electronic educational platform, in accordance with Federal Law No. 398 of March 14, 2020 "On the activities of organizations under the jurisdiction of the Ministry of Science and Higher Education of the Russian Federation, in the context of preventing the spread of a new coronavirus infection on the territory of the Russian Federation (Federal Law, 2020).

At the present stage of development of methods and means of digital communications, the task is to integrate educational and methodological materials within the framework of distance learning, the formation of prerequisites for the training of specialists who have been trained using innovative methods, using new educational tools. We can note the blurring of the boundaries between traditional and distance approaches both in education in general and in particular, for example, in teaching foreign languages. The purpose of the article is to study and analyze various methods in teaching translation, abstracting of special texts, rendering translation and mediation in the current unusual conditions of self-isolation.

\section{LITERATURE REVUE AND METHODOLOGY}

During the spring semester 2020 teachers were forced to conduct classes only online, partially using a hybrid method combining full-time and distance learning, which showed good results in teaching foreign languages, in particular, translation and abstracting of special texts (Peraya, Peltier, 2020). Hybrid learning combines full-time and distance learning in one educational communicative scenario and assumes an active nature of teaching, interaction with students of the same course and different courses, contact with the teacher, both offline and online. Over the past twenty years, the hybrid method has been increasingly used in higher education. Numerous studies have been devoted to this topic (Nissen, 2019, Benetos, Peraya, 2015, Charlier and Deschryver, 2012, Alonso Vilches, Detroz, Hausman, Verpoorten, 2020). Hybrid learning assumes an active role for both the teacher and the student in both forms of education (full-time and distance learning). However, the role of the teacher is principal and defining. The student is given a central place in the learning system, an active educational approach is applied, the goal of which is the quality and flexibility of education, and interaction in the learning process of the teacher and the student (Boelens, Voet, De Wever, 2018, Burgos, 2020).

Teachers using the hybrid method enable a student who has missed classes for any reason to complete the assignment in electronic form and interact with the teacher and other students online (Pogent, Albéro Guérin, 2019). In hybrid learning, students can contribute to the proposed communication scenarios by mastering and using digital technologies (Halverson, Graham, 2019). When applying this method, students should feel comfortable enough, clearly understanding how to achieve their goals, establishing connections between various elements of learning. Interaction between teacher and student, both online and offline, is an important communicative aspect of the pedagogical scenario that must be fully thought out, planned and integrated as a full-fledged component of hybrid learning (Manoïlov, 2019). As stated above, the hybrid teaching method ensures the continuous nature of education (Benetos, Peraya, 2015).

Some teachers propose integrating distance learning into traditional education precisely to ensure the continuity of the teaching process, for example, if the teacher is unable to conduct a face-to-face lesson, when the teacher goes on a business trip, or when students are on an internship, which allows the latter to actively participate in various educational scenarios remotely. Student surveys show that a lesson is perceived as "structured and well-organized" if, despite its complexity, the instructor provides comprehensive support. It should be noted that the proposed educational material should be interesting, informative and motivate students for further work. The communication scenario of work on-line refers to the methods of work and interaction with students and colleagues in both modes, in person and in absentia, and provides for a combination of synchronous and asynchronous actions in each of the modes (time factor). Distance learning provides a certain amount of freedom and choice (asynchronous distance, time and pace of work). The distance nature of hybrid courses is mostly asynchronous and provides students with the opportunity to decide for themselves when they will be able to complete assignments by the deadline. If the lessons are held, for example, in the videoconference mode, then this lesson is synchronous.

With online learning, students should be able to plan the timing of assignments, and not prepare them at the last minute before class, which significantly reduces the effectiveness of learning the material. Synchronous 
and asynchronous modes of operation are of a pronounced communicative nature. Many students prefer the direct nature of the synchronous mode of learning over asynchronous, which was confirmed by a survey of RUDN University students conducted by the authors of the article: distance learning is perceived as providing more freedom and choice of actions (43\%), but, however, full-time education with a teacher prevails $(57 \%)$. Thus, there is a certain relationship and a relative balance between these modes and online classes can be included in the overall schedule of classes. Students will be able to use the skills and abilities acquired during training in the hybrid scenario in their future professional activities. Writing skills acquired in online classes can be practiced in various ways, depending on the goals and objectives, for example, writing various essays, written messages on a specific topic related to the future profession, etc (Nissen, 2019).

For the development of oral skills (listening, speaking), various speech exercises are offered that will motivate the student to communicate. These tasks include viewing and subsequent discussion of various fragments from programs on French television, holding round tables, talk shows on issues related to the specialization of students. An important stage of training is the control of the degree of mastering by the student of new material. One of the forms of checking lexical and grammatical skills is various online tests. After conducting an online lesson, the teacher should select and send to the student's e-mail homework in electronic format, which he must independently complete and send to his teacher for verification on time before the start of the next lesson. Then the teacher corrects the work of each student with subsequent analysis in the next lesson. Homework should be regular, informative, aimed at practicing and mastering the knowledge, skills and abilities acquired in on-line classes.

If the main stages of work in the process of an online lesson such as a competent setting of goals, objectives, the choice of work methods and material are preserved, a number of positive points can be noted:

- since students are at home in a familiar environment, there is no stiffness while communicating with the teacher, which contributes to more effective assimilation of the material;

- the teacher can offer additional thematic material from various French-speaking on-line sources with subsequent control;

- the student can listen to the recorded online lesson at a convenient time the right number of times, making the necessary pauses for a better understanding and assimilation of the material.

In preparation for online learning, the teacher selects additional material that can be used in electronic format with the help of additional option "screen sharing" and offer it for various types of work, including practicing various types of oral and written presentation of opinions on the topic under study. Since online classes can be stressful for some students, it is important to form positive emotions that help maintain interest in the subject, faster memorization of the material. Students get the opportunity to develop skills such as tolerance, the ability to listen to the interlocutor, the desire to understand the other, the willingness to seek a compromise solution and respect others' opinions.

In the modern information and communication environment, the scientific style of speech, analytical reading and abstract writing are becoming increasingly important. These most important types of speech activity are present when working with special texts in the semantic processing of the text, which is necessary for the student's research activities. For teaching translation and abstracting, thematic training materials are offered, which contain special texts for translation, tests and exercises to consolidate a particular topic. A student who speaks a foreign (French) language at the B1+, B2 level must be able to translate and abstract special texts.

Translation consists primarily of the work of understanding and analyzing the original text, representing a threefold process: understanding, deverbalization, re-expression of meaning. Translation means the use of linguistic competence, discursive, referential, socio-cultural skills for communication. The stages of the translation process (understanding the source text, cultural and linguistic mediation, formatting the target text) are not seen as a simple sequence of decoding and re-encoding messages, but as complex restructuring processes. Any translation is inscribed in specific socio-historical conditions and takes into account the norms of acceptability of the host culture (Seleskovitch, Lederer, 2014).

During the period of distant learning, students translated texts in their specialty and sent it by e-mail to the teacher before receiving the next test task. When conducting lessons on teamwork, the translations performed were also placed in the cloud so that all students in the group could familiarize themselves with the possible translation options, and then, during the lesson with the teacher, students reasonably chose the best option from the proposed ones. In the on-line classes, the teacher commented on homework: he 
analyzed educational texts, typical mistakes of students, explained the peculiarities of translation) and gave appropriate recommendations for further work. Students took an active part in the online discussion, asking questions related to translation difficulties, exchanging views with the teacher and colleagues in the group.

Teaching abstracting/rendering as the most important type of speech activity, work with foreign language texts, is necessary to prepare students for research activities. Abstract translation (rendering), abstracts (summary) of several texts on a specific topic are the result of processing texts on a specialty in a foreign language. Students should acquire the skill of information compression, which is essential in research activities, performing exercises and assignments suggested by the teacher.

In the French language classes at the non-linguistic faculties of the RUDN University, texts of various genres are offered for abstract translation, for example, literary, media, journalistic, as well as scientific texts on the relevant topic of the studied specialty. As a result, students must submit an informative abstract (abstractsynopsis), which contains in a generalized form all the main provisions of the primary document. In the course of abstract translation, the student carries out semantic or informational processing of the text. Subject-logical information should be preserved during abstract translation. Students learn to maintain consistency by using connectors and organizing information in paragraphs correctly. The genre of abstract translation helps to maintain the context of the professional situation, teaching the culture of translation and forming the student as an independent researcher.

The system of teaching abstract translation allows forming students' readiness for further professional communication in a foreign language and provides for the implementation of special exercises. When translating from a foreign (French) language into a native (Russian) language, the student must learn to use a scientific style of presentation. To develop the relevant skills, scientific texts of the relevant subject are used, as well as abstract articles from scientific francophone journals. Subject-logical information is stored and transmitted in the process of abstract translation, while expressive and evaluative information is omitted. Referencing is closely related to the process of curtailing information and reducing its volume. Abstract translation of texts plays an important role in the process of preparing students for independent scientific activity. Consecutive work on an abstract translation forms the skill of abstracting the source text. The abstract translation genre helps to model the context of a professional situation.

\section{EXPERIENCE}

During the quarantine period, students were trained not only in oral and written special translation, but also in language mediation as a type of communicative activity that has a cultural component. Mediation (linguistic mediation) can be carried out by reformulating in the form of a summary or report. Mediation activities include (oral) interpretation and (written) translation, as well as summarizing and reformulating texts. Linguistic mediation involves planning, text organization, translation analysis and preparation of a thematic glossary (CEFR, 2000). Mediation is a spontaneous human activity that meets several requirements: on a practical level, it allows speakers to make contact. From a psychological point of view, as a transcoding operation, it is the basis of all value determination activities. Translation inserted into this general structure is a much more complex process than a simple search for equivalences between words from different languages, especially since each language reflects the cultural and psychological specificity of the community. It is in the activity of mediation, interpreted in a broad sense, that discourse elements related to the cultural aspect, defined as "untranslatable" in language, arise (Burgos, Dumas, Remond, 2020), Mediation aims to develop written and oral language skills and the acquisition of knowledge required for interlanguage and intercultural mediation (translation (in writing) and interpretation (oral)) special texts using skills such as memorization, note-taking, etc. to acquire practical competence. Students translated specific texts and presented their content in a structured manner. To guarantee mediation without vocabulary and in highly specialized fields, you must have a B2 level.

Linguistic mediation, focused on the transmission of the message, avoids some of the errors of literal approach of certain texts and documents. Mediation is viewed as a "natural" linguistic communicative act, when the interlocutors during the exchange of information can resort to understand each other, using such means as reformulation. To develop and improve translation skills during the online training period at Covid19, students receive the following assignments:

- regularly keep a journal containing different versions of the translated texts,

- compile a thematic glossary with the most frequently encountered special terms, phraseological expressions,

- make a list of difficulties encountered during translation, which develops students' independence and self- 
esteem when performing translation,

- edit the text, taking into account the comments made by the teacher,

- be able to determine the pragmatic value of texts, cultural aspects transmitted through the language, analyze the pragmatic factors of the source text and final texts,

- make decisions on the structural organization of the text, syntax, genre of the source text, for transformation into the final text,

- use different types of translation in accordance with different socio-cultural contexts when switching from one language to another (direct translation: borrowing, tracking, literal translation; equivalence adaptation, etc.),

- use one-, two-, multilingual dictionaries (paper and online versions, glossaries; lists of abbreviations, including international ones),

- to analyze lexico-syntactic connections, synonyms and antonyms and their functioning in languages.

\section{RESULTS}

The experience of teaching translation and abstracting of special texts in a foreign language during the period of self-isolation has shown that in the future online classes will be increasingly used. Traditional pedagogical approaches have provided quality teaching in translation and abstracting of special texts, partially using digital technologies (hybrid method). However, during the Covid-19 quarantine in the spring semester 2020, teachers completely switched to online learning and the use of only digital technologies, ensuring the principle of lifelong education, since most of the students were forced to go home to other cities and countries.

During the pandemic, RUDN used the educational platform Microsoft Teams (an online application for "Office 365 ") to ensure the continuity of the educational process. For example, the teacher and the student communicated via video communication in the format of an oral discussion on the text proposed for translation and abstracting. If the translation and abstracting of the video text was offered as homework, the student had the opportunity of multiple individual viewing of the material, which, undoubtedly, can be attributed to the advantages of the remote model of conducting classes. If there were any questions while watching the video, students had the opportunity to contact the teacher and ask him questions. The obligatory form of conducting online classes for all students and teachers of RUDN University in the spring of 2020 using this platform made it possible to improve this platform and supplement it with additional options.

\section{CONCLUSIONS}

At the present stage of development of methods and means of digital communications, the task of integrating educational and methodological materials within the framework of the concept of distance education involves the phased introduction of distance technologies into the part-time training system. Perhaps in the future, education will be continuous regardless of where the student is. The complete disappearance of the boundaries between traditional and distance approaches in education remains a matter of time, therefore, the prospects for further research in this area depend on the quality and capabilities of the educational platform and the increase in the number of users in the system. Application of digital educational technologies and traditional pedagogical approaches within the framework of ensuring the concept of lifelong education helps to solve the problem, regardless of the territorial affiliation of the teacher and student. Having analyzed the technical possibilities of ensuring the transfer of information, we can conclude that a complete transition to a distance learning format in the fields of jurisprudence, social and humanitarian relations is a question of the future. Application of a hybrid teaching method allows you to better control the work of students, to solve the problem of absence in the classroom.. The survey among students showed that the combination of on-line and off-line learning modes is the most successful.

Our experience has confirmed that the combination of full-time and remote modes gives good results in teaching translation and abstracting of special texts in a foreign language, taking into account the level of training of students. Therefore, we can conclude that distance learning during a pandemic helps to solve some psychological problems, expands the communicative sphere, and contributes to the development of motivation to learn. Translation, as a separate discipline, occupies a prominent place in language teaching, and has adapted better than other disciplines to the modern requirements of online learning.

Thus, we can conclude that the crisis had a positive impact on the renewal of forms of education and strengthening of the bond between teacher and student. The modernization of pedagogical processes, the 
development of digital technologies in the field of a gradual transition to a distance learning format associated with the widespread use of digital tools have contributed to innovation and the emergence of new forms of learning, taking into account the growth of initiative and independence of students.

\section{REFERENCE LIST}

Federal Law No. 398, (2020). On the activities of organizations under the jurisdiction of the Ministry of Science and Higher Education of the Russian Federation, in the context of preventing the spread of a new coronavirus infection on the territory of the Russian Federation . https://www.minobrnauki.gov.ru/ru/documents/card/?id_4=1065

Peraya, D., Peltier,C. (2020). Ce que la pandémie fait à l'ingénierie pédagogique et ce que la rubrique peut en conter, Distances et médiations des savoirs. http://journals.openedition.org/dms/5198

Nissen, E. (2019). Formation hybride en langues. Articuler présentiel et distanciel. Paris: Didier.

Benetos, K., Peraya, D. (2015). Guiding Professional Life-long Learning Projects. The Case of an Immersive Blended Learning Certificate. Canadian Journal of Learning and Technology. DOI : 10.21432/T2H045

Deschryver, N., Charlier, B. (2012). Dispositifs hybrides, nouvelle perspective pour une pédagogie renouvelée de l'enseignement supérieur. http://archive-ouverte.unige.ch/unige:23102

Alonso Vilches, V., Detroz, P., Hausman, M. et Verpoorten, D. (2020). Réception de la prescription à "basculer vers l'eLearning" en période d'urgence sanitaire. Une étude cas. Journal international de recherche en education et formation, Numéro Hors-série, 5-16

Boelens, R., Voet, M., De Wever, B. (2018). The design of blended learning in response to student diversity in higher education: Instructors' views and use of differentiated instruction in blended learning. Computers \& Education, 120, DOI : 10.1016/j.compedu.2018.02.009

Burgos,D. (2020). L'apprentissage en ligne, une réelle avancée pour une éducation innovante. Distances et médiations des savoirs. http://journals.openedition.org/dms/5152

Pogent, F., Albero, B. et Guérin, J. (2019). Transformations professionnelles et personnelles en situation de formation hybride. Distances et médiations des savoirs, 26. DOI: 10.4000/dms.3604

Halverson, L. R., Graham, C. R. (2019). Learner Engagement in Blended Learning Environments: A Conceptual Framework. Online Learning Journal 23 (2), 145-178.DOI: 10.24059 / olj.v23i2. 1481

Manoïlov, P. (2019). Mise en place de formations hybrides en langues vivantes et accompagnement des étudiants à la transformation numérique. Études de linguistique appliquée, 193(1). DOI : 10.3917/ela.193.0059

Benetos, K., Peraya, D. (2015). Guiding Professional Life-long Learning Projects. The Case of an Immersive Blended Learning Certificate. Canadian Journal of Learning and Technology, 41(4). DOI: $10.21432 / \mathrm{T} 2 \mathrm{H} 045$

Seleskovitch, D., Lederer, M. (2014). Interpréter pour traduire, de 5e edition, Les Belles Lettres, Paris

CEFR https://rm.coe.int/cecr-volume-complementaire-avec-de-nouveaux-descripteurs/16807875d5

Burgos,D., Dumas, Ph., Remond,E. (2020). Entretien avec la Professeure Belinda Tynan, Distances et médiations des savoirs. http://journals.openedition.org/dms/5146; DOI:

https://doi.org/10.4000/dms.5146 Linguistic 